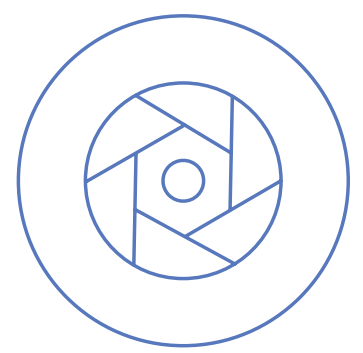

Nutrients do not appear in nature in isolation. Thus, it is safe to assume that they do not work in isolation

Ann Nutr Metab

\title{
Nutritional Factors in Fetal and Infant Brain Development
}

\section{Carol L. Cheatham}

Key Insights

Optimal maternal and infant nutrition during the period of early brain development is critical to the integrity and functioning of brain tissues. We are only beginning to understand the importance of the timing, dose, and duration of specific nutrients in human early brain development. Each nutrient has its own critical/sensitive time period when deficiency can lead to a cascade of negative impacts on early brain functional development, also known as the sensitive period. This article reviews the available data on the importance of folate, iodine, iron, vitamin D, choline, and docosahexaenoic acid (DHA) on early brain development during preconception, pregnancy, and the first years of life.

\section{Current knowledge}

As one of the most important organs in the body, the brain requires a high level of nutrition for optimal function. After birth, brain development continues well into the second decade of life (then, optimal nutrition is needed to protect against the onset of aging), highlighting the need to support the brain throughout an individual's lifespan. Classic examples to illustrate the importance of pre-conceptional maternal nutrition in fetal brain development are folate and iodine. During infancy and early childhood, iron deficiency has been shown to cause long-lasting, irreversible damage to neural tissue function. Emerging data suggest that DHA and choline act synergistically with other nutritional factors (such as uridine) to support neuronal plasticity during pregnancy and after birth.

karger@karger.com

(c) 2020 S. Karger AG, Basel

www.karger.com/anm

\section{Karger $\stackrel{2}{\circ}$}

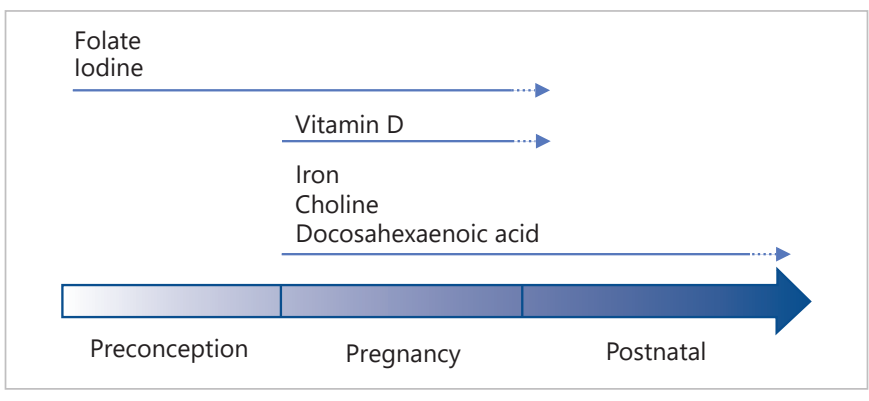

Key nutrients that support fetal and infant brain development from preconception to pregnancy and after birth.

\section{Practical implications}

New evidence indicates that folate may not be the only B vitamin critical for preventing neural tube defects in the fetus. The greatest impact on reducing the risk of neural tube defects comes from intake of methionine, choline, and betaine in combination with folate, rather than folate alone, before conception, underscoring the importance of overall optimal nutrition. During pregnancy, the fetus is entirely reliant on maternal provision of key nutrients, such as vitamin D and iron. Fetal demand for DHA is highest in the third trimester. The need for many of these nutrients, including iron, DHA, and choline, persists after birth. Therefore, women of child-bearing age should understand that optimal nutrition is a continuum that spans the preconception period, pregnancy, and across the early years of a child's life.

\section{Recommended reading}

Cheatham CL, Sheppard KW. Synergistic effects of human milk nutrients in the support of infant recognition memory: an observational study. Nutrients. 2015 Nov;7(11):9079-95. 